\title{
A MUDANÇA, A RESISTÊNCIA E A PERSISTÊNCIA DOS TÉCNICOS DO NEPI DE UM EX- DISTRITO DE SAÚDE DO MUNICÍPIO DE SÃO PAULO*
}

\author{
Lourdes Bernadete dos S. P. Alexandre ** \\ Maria Josefina Leuba Salum***
}

\begin{abstract}
RESUMO: O trabalho tomou como objeto de estudo o trajeto dos Núcleos de Epidemiologia Pesquisa e Informação (NEPI) do antigo Distrito de Saúde Tucuruvi/ Jaçanã, período 1991-1996. Adotou como referência a categoria modelo tecnoassistencial, reconhecendo o objeto de estudo na relaçăo dos sujeitos sociais com a gestão pública e desdobramentos na saúde e com os saberes/práticas nucleares inscritos na realidade estudada. Dois projetos políticos distintos nutriram a trajetória dos NEPIs. Os NEPIs nasceram, em 1991, na gestão Erundina, sob a experiência da distritalizaçäo. Cresceram, até 1993, em torno de experiências fundadas nas tradicionais atividades de vigilância epidemiológica na perspectiva de transitar para a vigilância à saúde. A interrupção formal da municipalização, no início da gestão Maluf, não foi suficiente para desviar a rota de estruturação dos NEPIs. Sobreviveram até 1996, resguardados pelos conteúdos e práticas construídos na gestão anterior. Mesmo limitados rumo à implantação da vigilância à saúde, aperfeiçoaram-se no processamento da informação, mantendo minimamente as atividades clássicas de Vigilância Epidemiológica. As evidências deste trajeto de "sobrevivência" estão demarcadas na Instrução Normativa 003/96, publicada no final da gestão Maluf, que privilegia atividades iniciadas na gestão Erundina. A trajetória destes NEPIs foi inquestionavelmente estruturada pela mudança e resistência de todos e de cada um. No limite de suas forças, ainda que por vezes confusos, mantiveram-se coesos e, num movimento de reação coletiva, não se frtaram a integrar "um novo modo de pensar e agir em saúde".
\end{abstract}

PALAVRAS-CHAVE: serviços de saúde; atividade epidemiológica; políticas públicas; Sistema Único de Saúde; práticas sociais em saúde.

\footnotetext{
* Este artigo concentra os principais conteúdos da Dissertação de Mestrado intitulada “A trajetória dos Núcleos de Epidemiologia Pesquisa e Informação no Municipio de São Paulo no periodo 1991-1996: o caso do Distrito de Saúde Tucuruvi/Jaçanã", apresentada em 22/7/1998 junto ao Programa de Pós-Graduação - Nível Mestrado, Área de Concentração de Enfermagem de Saúde Coletiva, da Escola de Enfermagem da USP. Seu resumo foi apresentado no IV Congresso Brasileiro de Epidemiologia, em 1998, no Rio de Janeiro, tendo a ele sido conferido Menção Honrosa.

** Mestre em Enfermagem, Assistente Técnico II, NEPI/ARS-7, Coordenação de Enfermagem, PMSP. Professora da Escola de Enfermagem Santa Marcelina e da Universidade Bandeirante de São Paulo.Telefone: (011) 2020805

*** Doutor em Ciências, Professora do Departamento de Enfermagem em Saúde Coletiva junto aos Programas de Graduação e Pós-Graduação em Enfermagem - EEUSP.Telefone: (011) 30667657Telefax: (011) 30667662 E-mail: mjlsalum@usp.br
} 


\section{INTRODUÇÃo}

Este trabalho recupera parte da história de alguns dos Núcleos de Epidemiologia Pesquisa e informaçăo (NEPIs) da regiāo norte do Município de São Paulo, cuja construçäo começou a ser projetada no ano de 1989, quando a eleição de um representante do Partido dos Trabalhadores (PT) trouxe para a nossa cidade uma nova experiência de gestão pública local. Na gestão Luiza Erundina (1989-1992), o Municipio de São Paulo passou a ser espaço de concretização das premissas que o Movimento da Reforma Sanitária havia proposto: assumir a saúde enquanto direito social inscrito na operacionalização da política social pública (COHN, 1995; GERSCHMAN, 1995). Pautada no projeto de descentralização na saúde, uma reforma administrativa alterou, em 1989, o nome e a estrutura daquela que era a Secretaria de Higiene e Saúde do Municipio. A Secretaria Municipal de Saúde (SMS) iniciou então o processo de implantação das Administrações Regionais de Saúde (ARS) e, posteriormente, dos Distritos Sanitários (DS) (COHN et al, 1993).

Imprescindivel era construir uma base de dados epidemiológicos que pudesse informar e produzir a intenvenção em saúde. Data de 1989, a criaçāo do Centro de Epidemiologia Pesquisa e Informação (CEPI) que, em estreita relação com os NEPIs teria como tarefa histórica articular, no processo de municipalização, uma nova estratégia de intervenção em saúde: a Vigilância à Saúde (SÃo PAULO, 1990; SÃo PAULO, 1991; SÃO PAULO, 1992B). Foi contudo somente próximo do final da gestão Erundina, no ano de 1991, que os NEPIs entraram em pleno funcionamento, a principio nas ARSs, expandindo-se, em seguida, para os DSs.

Os NEPIs do DS Tucuruvi/Jaçanã foram se instalar em um espaço-território da Zona Norte do Município de São Paulo, no recém-criado DS pertencente a ARS-7, cuja área abrangia quatro distritos administrativos: Tucuruvi, Tremembé, Vila Medeiros e Jaçanã. Seis dos 7 NEPIs de UBSs localizados, um a um, em cada UBS de gerenciamento municipal, mantinham relaçőes de auxílio técnico com o NEPI da sede do DS Tucuruvi/ Jaçanã, que gerenciava as unidades municipais da área. A UBS de Tucuruvi, tardiamente municipalizada, nunca alçou constituir um NEPI mais estável. Formadas em meio ao processo de realocação de todos os trabalhadores da saúde, as equipes dos NEPIs de UBSs e do NEPI Distrital abrigaram técnicos de formação diversa: médicos, enfermeiras, assistentes sociais, auxiliares de enfermagem, entre outros. A elas cabia o trabalho de: planejamento, execução, controle e avaliação das açōes e atividades da área de epidemiologia e vigilância à saúde, estando aí inclusas as atividades de vigilância 
epidemiológica; aos técnicos do NEPI Distrital, somava-se ainda a responsabilidade de conduzir as açöes de coordenação das atividades técnicas, além da prestação de auxílio, quando necessário, aos NEPIs da região (SÃO PAULO, 1991).

A eleição de Paulo Maluf, "produziu mudança total de orientação (...) [abalando] os avanços anteriores de processo de municipalizaçäo (...) [resultando na] regressividade das mudanças políticas inauguradas (...) [durante a gestão Erundina]" (GERSCHMAN, 1995, p.161). Desintegrou progressivamente a estrutura sobre a qual o governo petista buscara responder ao apelo dos movimentos sociais que, desde o final do regime autoritário, reivindicavam um resgate da divida social acumulada (GERSCHMAN, 1995; OLIVEIRA, 1997; SADER, 1995a). Os NEPIs do DS Tucuruvi/Jaçanã mantiveram-se em atividade, a duras penas, até a implantação do Plano de Atendimento à Saúde (PAS) na região, em maio de 1996. Quando isso aconteceu, as equipes dos NEPIs foram transferidas para o NEPI da ARS que, por determinação normativa, deveria passar a se responsabilizar pela vigilância epidemiológica de toda a regiâo norte đo Municipio de São Paulo. Em permanente tensão com o projeto que sucateava e desmontava os serviços públicos de saúde (GERSCHMAN, 1995), no período de 1991-1996, um conjunto diverso de práticas e saberes preencheu as atividades dos NEPIs, buscando ater-se ao projeto político-tecnológico que gestara o núcleo institucional

Voltando o olhar para esse passado tão próximo e ao mesmo tempo tão fugaz, tomamos como objeto de estudo o processo de construção e desenvolvimento dos NEPIs do DS Tucuruvi/Jaçanã, (período 1991-1996), para descrever e analisar uma história hoje quase que tão somente compreendida pelos sujeitos sociais que os instituíram, já que com a implantação do PAS, a maior parte da documentação foi ficando indisponível. A teorização sobre modelo tecno-assistencial construída por MEHRY (1992) possibilitou recompor esta história: na verdade, a categoria permite reconhecer o objeto das açסes de saúde, os caminhos de atuaçăo possiveis para se interferir no problema e a organizaçăo do poder politico na forma da produçăo de serviços de saúde. Assim sendo, instrumentalizou-nos para reconhecer o que designamos como dimensáo polfitica - as relações que os sujeitos sociais estabeleceram com a gestão pública e seus desdobramentos no âmbito da saúde - e a dimensăo tecnologica - as relaçōes que os sujeitos sociais estabeleceram com os saberes e práticas nucleares de saúde sob os quais construíu a ação epidemiológica. Nesse sentido, foi possivel evidenciar na ação política e tecnológica as possibilidades e os limites da construção do novo. 


\section{ASPECTOS METODOLÓGICOS}

Nossas fontes de informações foram os depoimentos de sujeitos sociais que instituíram o NEPI Distrital e os NEPIs de UBS e a documentação oficial publicada em Diário Oficial do Município (DOM) que mais abrangentemente normatizou suas atividades. Ao todo foram entrevistados 8 técnicos de nivel superior, que permanecem ainda hoje, em sua maioria, no NEPI da ARS-7, 5 médicos, 2 assistentes sociais e 1 enfermeira que, durante a gestão Erundina e durante a gestão Maluf, além de participar da execução das ações próprias de cada núcleo, foram os responsáveis pela coordenação técnica do projeto de implantação e desenvolvimento dos NEPIs.

A partir de pesquisa direta nas publicações do DOM e busca ativa nos arquivos computadorizados da Biblioteca Legislativa do Município de São Paulo, no decorrer do período de 1989 a 1996, selecionamos o Decreto n $31723 / 92$ de 15/06/92 (SÃO PAULO, 1992) e a Instrução Normativa 003/96 ASPLAN/PLAN de 31/05/96 (SÃO PAULO, 1996), que remetiam-se às atividades mais gerais de Vigilância à Saúde, em torno da qual os NEPIs construíram as ações epidemiológicas, de pesquisa e de informação.

Os depoimentos foram colhidos em entrevistas, tomando como referência o período 1991-1996. Aos depoentes eram formuladas 8 questões acerca da constituição dos NEPIs, suas finalidades, concepções estruturantes, atividades executadas, sua produção específica e impacto no controle de saúde do território, dinâmica de informação, estratégias de envolvimento dos técnicos e transformações produzidas. $A$ análise foi fundamentada nas recomendações mais gerais de MINAYO (1994 a e b), nos exercícios de tematização de BARDIN (1977) e nos encaminhamentos de análise de MAINGUENEAU (1993) que nos instrumentalizou na busca das heterogeneidades constitutivas ${ }^{1}$, entre a base empírica e a base teórica. Identificamos então no interdiscurso os conteúdos que se evidenciaram como ilustrativos da história dos NEPIs. A nossa base teórica foi constituída a partir do estudo de um elenco selecionado de referências bibliográficas que trataram tanto da dimensão política quanto da dimensão tecnológica em saúde. A nossa base empírica se constituiu a partir das formaçס̃es discursivas que

1 Afirmar que existe uma heterogeneidade constitutiva "consiste em propor ao analista o interdiscurso como objeto e fazê-lo apreender, de imediato, não uma formação discursiva, mas a interação entre as formações discursivas. (...) [Significa que] um discurso não nasce, como geralmente é pretendido, de algum retomo às próprias coisas, ao bơm senso, (...) mas de um trabalho sobre outros discursos" (MAINGUENEAU, 1993, p.119-20). Parte do pressuposto que um discurso (o da base empírica - o dos depoentes e da documentação analisada) "constitui-se a partir de uma série de operações" (MAINGUENEAU, 1993, p.121) sobre outro discurso (o da base teórica). 
evidenciaram como os sujeitos sociais (através das suas descriçöes do que foram os NEPIs) e o texto da lei (através das "regras" que normatizaram a ação propriamente tecnológica dos NEPIs) privilegiaram no trajeto de construção destes núcleos os projetos políticos e tecnológicos característicos de cada gestão no período estudado.

\section{A HISTÓRIA dOS NEPIS E A DIMENSÃO POLITICA: A DIVERSIDADE DAS DIRE- TRIZES GERAIS}

Ao analisar a constituição e o desenvolvimento dos NEPIs na sua dimensăo politica, é preciso reconhecer que posturas radicalmente contrárias, engendradas na gestăo Luiza Erundina e Paulo Maluf, só poderiam embasar políticas e práticas de saúde opostas. Enquanto a gestăo Erundina colocava-se como uma administração democrática a serviço das grandes massas (COUTO, 1995), o governo Maluf pretendeu "ser a vitrine de uma direita renovada, que tem no social um aspecto importante de seu programa (...) acoberta[ndo] (...) o velho malufismo voltado para governar em prol de minorias privilegiadas" (GENOINO, 1996, p. 1).

depoimento 3 - "(...) quando eu entrei tinha uma diretriz e isso foi importante (...). Tinha uma diretriz, coisa que se perdeu na outra gestáo".

O governo municipal de Luiza Erundina manteve uma proposta afinada com a lógica da política pública de saúde, concretizada na criação do Conselho Municipal, na participação da sociedade nos vários niveis de decisão e na promoção da municipalização das ações de saúde (BITTAR, 1992; COUTO, 1995). O projeto político empunhado por Paulo Maluf estruturou o setor sob a lógica de mercado, promovendo uma "mudança radical nos rumos definidos para o setor da saúde (...) sendo que as duas últimas gestões a opção por transplantar a lógica privada para o setor público torna-se clara" (COHN \& ELIAS, 1997, p.77). Esse antagonismo perseguiu o processo de construção dos NEPIs.

depoimento 1 - "(...) com a Constituiçăo de 88 cabia ao municipio todas as açбes relacionadas à promoçăo da saúde, prevençăo da doença. (...) al nós partimos para estruturaçăo (...) essa visăo caminhou bastante no pensamento e discussăo até o fim do governo Erundina, mas com o advento da chegada do Maluf, as pessoas (...) acharam que um pensamento tăo amplo sర daria certo em um governo que tivesse uma responsabilidade, que tivesse realmente um intuito de fazer as coisas realmente acontecerem, 
o que a gente já sentia e sabia que nåo iria acontecer com o govemo Maluf (...) foi um governo desastroso."

No período de 1991-1992, o projeto do govemo democrático do PT buscava construir suas diretrizes no "ideário de uma tradição republicana que insiste não só na eficiência da máquina governamental e na qualidade dos serviços, mas, sobretudo, na transparência e lisura administrativa, e ainda conseqüente separaçäo das esferas de interesse público e privado" (KOWARICK \& SINGER; 1993, p. 216). Calcadas no programa partidário, tais diretrizes foram integradas no projeto da gestão pública municipal de modo a: "inverter as prioridades orçamentárias, em beneficios das camadas populares; (...) apoiar a formação de conselhos populares e abrir canais de participação popular na Administração, democratizando a gestão petista; (...) colocar a administração ao lado das reivindicaçöes populares que dizem respeito à ação do Estado, pressionando o governo estadual e federal no sentido de atendê-las (...)" (COUTO, 1995, p.133).

Ditadas pelo Diretório Municipal do PT e assumidas pela administraçăo por ocasião da gestăo Luiza Erundina, essas inovações sofreram desvios de rota, pois, "a assunção paulatina da lógica de partido govemante significou a incorporação cada vez mais patente da ética da responsabilidade, em substituição ao principismo da ética da conviç̧ão. Isto se fez presente no cambiamento de lógicas de ação, (...) e também na postura assumida diante de certos dogmas contidos na linha política e no programa partidário originais" (COUTO, 1995, p.177). Construíram-se, contudo, algumas proposiçőes estratégicas: fundamentada num projeto de ação redistributiva trouxe para o Município a novidade de direcionar as ações públicas para 0 atendimento das necessidades de educação e saúde dos grupos de baixa renda (KOWARICK \& SINGER, 1993). Isso é tanto verdade que, ao lado das posições mais diretamente vinculadas aos limites encontrados durante a gestâo Erundina, a história dos NEPIs do DS Tucuruvi/ Jaçanã é também traçada pelos depoentes no conjunto das possibilidades que o projeto politico petista comportou.

depoimento 2-Eu acho que foio período mais prospero, (...) foi um período que a gente tinha a populaçáo do nosso lado (...) o Conselho de Saúde do Distrito. (...) hoje eu avalio especialmente aquele tempo de administraçăo, eu te digo que existem sucessos que ficaram marcados (...) e năo sáo sucessos de serem aplaudidos năo, săo sucessos de eu saber que participei da mudança, da implementaçăo e que isso mudou de verdade, nem que tenha sido por um perfodo, a qualidade de vida de uma populaçáo que eu tinha a obrigaçâo de atender", 
o que não quer dizer que a história dos NEPIs ficou livre dos problemas cotidianos enfrentados pela administração petista:

depoimento 2 - "(...) eu acho que a gente tinha pouquissima experiencia. Éramos todos muito principiantes".

depoimento 5- "(...) năo haviam recursos. Voce sabe que a administraçăo Luiza Erundina, a marca sempre foi custo zero."

Durante a gestăo Erundina presenciara-se um embate entre o projeto político que reinvidicava a justiça social e um outro que, utilizando todos os recursos disponíveis, consolidava uma sociedade de apartação social, com perpetuação do poder das elites e das mentalidades conservadoras (SADER, 1995b). "Nesse contexto, a administração petista sobressaiu positivamente (...) pela capacidade de utilizar o espaço institucional para colocar em andamento medidas distributivas sem dar-lhes o caráter populista tradicional na política brasileira, (...) colocando o Estado a serviço dos interesses da maioria da populaçäo. (...) Talvez a principal marca negativa do governo tenha sido uma certa falta de iniciativa, refletida na dificuldade de articular o processo administrativo à luta política mais geral" (KOWARICK \& SINGER, 1993, p. 215), fato que propiciou acusações à prefeitura, classificando-a de assumir posiģסes conservadoras em sua condução (COUTO, 1995, p.166).

depoimento 7 - "(...) dentro da assessoria da secretaria [Municipal de Saúde], tinha alguns pensamentos diferentes (...) tinha entrave dentro da secretaria porque ela nåo conseguia fazer que a prefeitura mudasse a estrutura administrativa".

Vários foram os ensinamentos extraidos pelo partido dessa experiência no Município de São Paulo: "(...) que a reversão de prioridades não poderia ser feita sem uma negociação com os detentores do capital e seus representantes políticos (...); (...) os interesses da maioria não são homogêneos (...) [0 que obrigou a administração a] ser mediadora dos conflitos que opõem entre si os vários segmentos dessa mesma maioria" (KOWARICK \& SINGER, 1993, p.211-212). Mas, ao lado das questões internas, a gestão Erundina enfrentou conflitos com o projeto de governo federal, em que já ganhava corpo a consolidação do projeto neoliberal que criava uma situação de financiamento desfavorável com relaçāo ao setor saúde, favorecendo uma cisão entre a proposta da carta constitucional e a implementação das políticas de saúde. Na prática, o que de fato era estimulado era a manutenção da privatização da saúde, com a expansão dos convê- 
nios médicos e o oferecimento de atendimento à demanda de forma excludente (BITTAR, 1992). A retirada do Estado da esfera dos direitos sociais era o contraponto para a investida paulista no espaço público em que o "Estado só deveria intervir com o intuito de garantir um mínimo de serviços para os pobres e produzir serviços que os privados não podem ou não querem produzir, além daqueles que a rigor são de apropriação coletiva" (COHN, 1995, p.163). Na história dos NEPIs, este enfrentamento não passou desapercebido:.

depoimento 1 - "(...) a nossa visăo em relaçăo à saúde ela vingou, mesmo que a Constituiçăo de 88 esteja sendo bombardeada pelo neo-liberalismo, o que nós plantamos , o que nós fizemos ninguém tira mais".

Na gestăo de Paulo Maluf, a adesão ao projeto neoliberal se mesclava às particularidades do projeto malufista: "a inversão de prioridades e os cortes em investimentos sociais acabaram se tornando sua marca registrada" (SEGATTO \& ROVAI, 1996, p. 39-40). Verbas antes destinadas aos setores sociais passaram a ser desviadas para sustentação das grandes obras (OLIVEIRA, 1997). "A prioridade dada às obras foi tão flagrante que teve de ser reconhecida, (...) pelo próprio 'bunker' malufista. (...) Os movimentos sociais e órgãos subordinados à prefeitura de apoio direto à população eram vistos como reduto de adversários políticos e, portanto, deveriam ser tratados como tal (...) o importante eram as obras (...) acompanhadas de forte dose de personalismo (...) prescindindo de um plano diretor para a cidade (...) [aparentemente] [des]preocupado com o impacto urbanistico sobre a cidade. O importante era o impacto publicitário" (SEGATTO \& ROVAI, 1996, p. 47, 80, 82-3-5)."

Muito embora a geståo Maluf tenha perseguido obstinadamente tais diretrizes, "Maluf percebeu, porém, que apenas grandes obras viárias não sustentariam seus sonhos mais altos." (SEGATTO \& ROVAI, 1996, p. 88). Buscando ampliar a sua base de apoio popular, questionado insistentemente pelo abandono do social, incluiu projetos voltados para as áreas sociais, preenchendo lacunas entre as suas promessas de campanha e as suas realizações. O Projeto Cingapura, considerado por SEGATTO \& ROVAI, (1996, p. 88) "uma das maiores farsas montadas pela administração", foi um projeto oneroso, de qualidade tecnológica discutivel e que não conseguiu atingir as metas propostas. $O$ outro projeto, o PAS, como veremos adiante, também não ficou longe das críticas: entre elas, "a quebra do conceito de universalidade (...) e a privatização da saúde. Foi censurado pelo Conselho Nacional de Saúde, por estar na contramão do 
SUS". (SEGATTO; ROVAI, 1996). A gestăo Maluf foi, enfim, marcada por denúncias de irregularidades, por endividamento público importante, utilização do setor e do dinheiro público para beneficiar a si próprio e a seus aliados, e por realização de contratos e concorrências públicos suspeitos, fazendo "da publicidade máscara para esconder 0 que deixou de realizar, (...) [mantendo e ampliando os] privilégios de uma minoria e [destruindo de forma] sistemática [OS] caminhos que levam à cidadania" (SEGATTO \& ROVAI, 1996, p. 128).

Muito embora os técnicos do NEPIs possam ter se apercebido da violência que representou o projeto malufista na dimensão mais específica da política pública de saúde, muito pouco se referiram à percepção das diretrizes da gestão Maluf rumo a um elenco de prioridades absolutamente opostas à da gestão Erundina. Tanto é que somente dois depoimentos apenas tangenciaram a questão, mesmo assim carregados da simplicidade de quem toma uma coisa por outra.

depoimento 1 - "(...) a gente viu por exemplo que o Hospital da Vila Maria foi dado para a Administraçăo Regional da Vila Maria, quer dizer que quem realmente mandava no hospital era (...) a Administraçáo Regional da Vila Maria através do vereador [da região], o de Santana idem. (...) cortou-se os comissionamentos principalmente em relaçăo as pessoas que eles percebiam politicamente".

depoimento 7 - “(..) o sentimento era de morte, (...) a gente năo vê uma luzinha no fim do túnel (...) outros grupos com outros interesses (...) as distorçס̋es, os desvios de verba (...) acho que o que falta mesmo são dirigentes administradores responsáveis, compromissados (...)".

Durante a gestão Maluf, as conquistas democráticas construidas na gestão anterior foram indelevelmente solapadas. Tinha a seu favor como cenário de fundo uma crise no plano econômico em nível nacional associada a uma crise do regime político num momento ainda processual de construção da cidadania (BARROS, 1996). MerguIhado no projeto neoliberal, o Estado brasileiro estava "muito mais comprometido com os interesses de grupos estrangeiros do que [com a garantia da] (...) soberania do país, (...) [d]o nivel do emprego ou estabelecer diálogo com a sociedade civil" (OLIVEIRA, 1997, p.95). Com isso é forçoso reconhecer que o projeto político de Maluf não estava muito aquém daquilo que o projeto de expansão e globalização do capitalismo impunha: fomentar a exclusão social de forma mais contundente em paises do terceiro mundo. $E$ assim a gestâo Maluf explorou as vantagens de se fundamentar em alguns "pilares das 
propostas neoliberais (descentralização, focalização e privatização) que [por] convergirem com genuínas demandas sociais, (...) [confundem e apoiam] mecanismos de restrição de direitos" (BARROS, 1996, p.9). O conflito entre a ruptura com o que o encaminhamento democrático da gestão Erundina havia construido, a resistência e a consolidação do encaminhamento do projeto da gestão Maluf está presente na história dos NEPIs, principalmente quando se vivenciou a implantação do PAS.

depoimento 7 - “(..) com a entrada do PAS, (...) apesar deles fazerem o discurso, (...) eles nåo tinham (...) essa preocupaçăo, (...) essa concepçáo de trabalhar, desenvolver um trabalho em equipe e com a comunidade".

depoimento 2 - "INJo auge so tinha o NEPI e o serviço social trabalhando.(...) a ponto de sobrar uma sala só para o NEPI e uma para o serviço social, os dois excluidos".

\section{A HISTÓRIA DOS NEPIS E O PROJETO POLITICO/ESTRATÉGICO MUNICIPAL DA SAÚDE: O PERIODO 1991-1992}

A geståo de Luiza Erundina, ao assumir a administração do Município de São Paulo, tinha como "desafio (...) implantar o SUS (Sistema Único de Saúde), conquista constitucional de 88" (BITTAR, 1992, p.139). Inspirava-se, pois, nos avanços proporcionados pela constituição de um campo de conhecimentos e práticas que emergira num momento em que as políticas e práticas sociais em saúde não davam mais conta do emaranhado de problemas e conseqüências sociais oriundas do processo de industrialização e urbanização desordenados nos países da América Latina (MACHADO \& BELISARIO, 1992) e em que as desigualdades sociais cresciam enormemente. Sua postura não poderia ser diferente, vez que "o partido [nascera] estreitamente ligado à sociedade civil, às mobilizações de suas organizações, às lutas das minorias, às reinvidicações libertárias" (SADER, 1995b, p.145).

Nesse sentido, os NEPIs nasceram com as mudanças quantitativas progressivamente construídas na gestão Erundina: a ampliação dos serviços, a melhoria da qualidade de atendimento, a democratização da gestão do sistema local (BITTAR, 1992), sendo "(...) perseguida uma maior integração dos serviços com distinta complexidade tecnológica, privilegiando-se as área periféricas e mais carentes" (COHN, 1995, p. 322). 
depoimento 1 - “(..) a administraçăo Luiza Erundina (...) resolveu assumir a vigilancia, (...) nós sablamos o número de favelas que tinham, os locais de enchente, 0 número de estabelecimentos que lidavam com comida".

depoimento 2 - "(..) năo existia nenhum mecanismo claro de contato, de fluxo para se comunicar, nada era registrado. Aí começou a preocupação (...) como organizar esse tipo de sistema.(..) a gente começou a trabalhar (...) mapas peribdicos da unidade [de] acesso ao público, (...) aos funcionários e (...) sempre para o movimento de saúde".

Para tanto, buscou como alternativa o apoio do "internacionalismo militante que caracterizou a relação entre países socialistas e as nações dos grandes impérios coloniais rumo a independência" (DIMEANA et al, 1995, p.13). Valeu-se da Cooperação Brasil-Itália para construir o seu projeto, que proporcionava colaboração "teórico-cultural, político-institucional e operacional, [uma cooperação constituída por uma nova visão] que se poderia definir como a que buscava valorizar as diferenças e os aspectos críti$\cos ^{n}$ (DIMEANA et al, 1995, p. 17). Tendo como premissa uma análise da Reforma Sanitária Italiana e da Reforma Sanitária Brasileira, seus sucessos e dificuldades, a Cooperação Italiana concentrou esforços no sentido de contribuir para a implantação do DSs no Município de São Paulo, a partir de experiência anterior em alguns municípios do Estado da Bahia. A experiência paulista da Cooperação Italiana nutriu pois o processo de criação dos NEPIs do DS Tucuruvi/Jaçanã.

depoimento 1 - “(..) esse programa da "Cooperativa Italiana" (...) era um diagnóstico de área (...), era um programa geral do Distrito".

A construção do projeto em Pau da Lima (BA) demonstrara haver necessidade de mudar a "lógica de organização da rede de serviços de saúde bem como [d]as práticas sanitárias ali desenvolvidas, [no sentido] (...) de reestruturação do poder e da divisão do trabalho no setor saúde e na sociedade em geral", realizando mudanças que permitissem maior eficiência administrativa e impacto nos problemas de saúde existentes na área (DIMEANA et al, 1995, p.18, 19): tinha tudo a ver com a proposta de descentralização dos SUS. Foi então que, no desenvolvimento da experiência da Cooperação Italiana no Município de São Paulo, foram criados os Distritos Sanitários (DS) e então organizados cursos de formação de gerentes e oficinas de trabalho com vistas à territorialização oferecidos nas regiöes de Campo Limpo e Itaquera (UNGLERT, 1995). Esperava-se que estas oficinas pudessem disseminar, através dos seus participantes, a experiência para as demais regiōes do Municipio. 
depoimento 7 - "(...) o distrito começou (...) com aquela proposta de territorializaçăo, de estar conhecendo melhor a área do distrito (...) a gente achava que tinha a cara de NEPI, (...) fazer a vigilancia à saúde da comunidade, conhecer os problemas de saúde daquela comunidade, reconhecer onde eles estavam localizados, reconhecer o territorio".

Estavam criadas condições de vital importância para o desenvolvimento de uma nova estratégia de atenção à saúde, a da Vigilância à Saúde. As mudanças progressivas, concentradas primeiramente no processo de distritalização, foram sendo alcançadas através do envolvimento dos técnicos na estratégia da territorialização o que constituiu a base do desenvolvimento dos NEPIs.

depoimento 2 - "A gente mapeava também (...) [a demanda] (...) que năo era absorvid[a] pelo PS e tinha que ser removid[a] (...) e aí nos descobrimos (...) com o passar do tempo (...) que a grande questáo de saúde da regiấo era a falta de leitos de matemidade, foi um período que a gente começou a se preocupar, de fato, com a questăo de um controle de saúde. Em decorréncia [dos] mapeamentos da área de risco, aquele processo que nos fizemos de diagnostico de saúde [iniciado com o trabalho fomentado pela Cooperação Italiana] (...), a gente começou a fazer uma identificaçăo real do quadro da problemática de saúde da regiâo".

A experiência da territorialização foi muito expressiva: quem dela não participou, teve mesmo dificuldade em compreender o conjunto de significados e o leque de possibilidades que o processo viabilizava para a consolidação dos NEPIs.

depoimento 8 - "(...) eu fui concursada em 1993 (...) e nunca participei de treinamento sobre territorializaçåo, nem diagnóstico de saúde. (...) Eu percebia que na unidade da prefeitura a concepção de NEPI era assim: se tivesse que fazer uma visita domiciliar era aquela equipe, tudo era aquela equipe. Os funcionários năo eram do NEPI, viam esse NEPI (...) como uma equipe chique. (...) eu achava isso equivocado".

Ao processo de distritalização e ao desenvolvimento da territorialização, seguiu-se o processo de construção do sistema de informação com base territorial e execução do planejamento estratégico, ferramentas centrais para mudar a organização do trabalho e, então fundamentar o conteúdo das práticas institucionais nos NEPIs.

depoimento 7- "(...) a gente esperava atuar em cima do que a gente tinha detectado no trabalho de temitorializaçăo, ir atrás do que a gente priorizou e chegar a uma 
avaliaçåo (...) trabalhar o planejamento local e ver se estava dando resultado, (...) rever as prioridades, (...) atingindo os resultados. (...) precisaria um tempo maior para as pessoas estarem assimilando, se conscientizando (...) e acabou nåo dando".

\section{A HISTÓRIA DOS NEPIS E NO PROJETO POLITICO/ESTRATÉGICO MUNICIPAL DA SAÚDE: O PERIODO 1993-1996}

Se a gestão Erundina construiu os NEPIs no projeto de distritalização, territorialização e vigilância à saúde, na geståo Malưf esse trabalho foi pendendo fôlego, abalando a rota anterior.

depoimento 7 - "(..) a gente acabou perdendo todo aquele trabalho da territorialização, do diagnóstico (...), năo houve tempo (...) hábil para solidificar esse trabalho, (...) eu acho que individualmente foi uma vivência em tanto, (...) nâo tem outro jeito, se a gente quer transformar a realidade local tem que ser assim. (...) com a entrada do PAS (...) aquela questăo de cada unidade ser responsável por algumas escolas de referéncia (...) acabou, (...) as escolas que se virem e tentem o atendimento individual".

Nas duas primeiras gestões da pasta da saúde durante o governo Maluf, "a saúde não configurava como um setor prioritário de atuação do govemo municipal" (COHN \& ELIAS, 1997, p.70): em meio a uma política de recursos humanos nefasta, interrompeu-se o processo de municipalização, retomou-se a centralização na distribuição das verbas e suas mazelas, menosprezando-se o Conselho Municipal de Saúde e os Conselhos Gestores (MOTTA, 1997; COHN \& ELIAS, 1997). Nessas circunstâncias, uma iminente paralisação dos serviços de saúde municipais deu força ao discurso da “ineficiência dos serviços públicos e entre eles da assistência à saúde prestada pelo setor público (...) [gestada] no descompromisso do funcionalismo (...) [e cujo] foco de mudança (...) [estaria] no modelo de gestão" (COHN \& ELIAS, 1997, p.4-5).

depoimento 1 - "(..): - Olha, vocês nâo valem nada; nós vamos mandar vocês para qualquer canto, até para uma usina de asfalto e nós vamos colocar aqui pessoas realmente boas! (E a gente viu as pessoas boas como ficou, é muito dinheiro público indo para o bolso deles). (...) nós sabiamos que nós estávamos sendo considerados como pessoas inúteis".

depoimento 3 - "(..) se eu nåo me engano na gestăo [Maluf] (...) foram pelo menos 5 diretores de ARS-7 e no mínimo 6 diretores de distrito. Se voce for contabilizar 
isso nos quatro anos, noves fora..., cada um via a coisa de um jeito, de uma forma, entâo o pessoal se sentiu perdido, por que năo tinha uma linha mestra, uma diretriz, ou quando tinham eram muito diferentes".

depoimento 6 - "Eu percebi que năo havia uma politica mais coletiva de saúde."

Na prática, o trajeto dos NEPIs na gestăo Maluf foi preenchido por aquilo que o projeto neoliberal propõe para a esfera dos direitos sociais: financiamento insuficiente, para engendrar um quadro de sucateamento dos equipamentos de saúde e criar a "necessidade de privatização" e de terceirização de serviços, com entrega dos equipamentos de saúde a organizações sociais e filantrópicas. "Economizando dinheiro da saúde, para aplicação em obras, criou a situação exata para que o célebre ditado 'é melhor isso do que nada' valesse" (OLIVEIRA, 1997, p. 12).

depoimento 2 - "(...) uma unidade que era referencia de tuberculose e em funçăo da reforma do prédio para a implantaçáo do PAS, ficou desativada por quase tres meses."

depoimento 3-"(...) depois de dois anos e pouco todo mundo desistiu. [e isso se justificava]: primeiro, se o que eu solicito nào vem; segundo, se o que eu preciso eu náo tenho e terceiro, ainda năo tem uma norma, uma diretriz".

depoimento 4 - "(...) dependia de uma coisa muito mais ampla que era a nova visăo que a cidade e a nova gestâo tinha que a saúde năo era prioritáia (...) no final da gestáo foi um problema tremendo, desinteresse da chefia, falta de viatura (...)".

Nesse sentido, ao transitar da administração Erundina para a de Paulo Maluf, no ano de 1993, os NEPIs foram profundamente abalados. No Município de São Paulo e no plano da saúde, o que principiou com uma prática de desestruturação paulatina dos serviços, culminou com a proposta legitimadora do PAS. Construído sob diretrizes derivadas de um diagnóstico do setor realizado pelo Banco Mundial, às quais não têm sido poupadas críticas (COSTA, 1996; LAURELL, 1995; POSSAS, 1996), o PAS alicerçourse " (...) numa proposta de três vertentes conexas: a) co-parceria na gestão de serviços de saúde (...), b) flexibilização administrativa da relação de trabalho (...) e c) financiamento provido por fundo público." (ELIAS \& COHN, 1998, p.170). Sintonizado com os pilares modernizantes das reformas contemporâneas do setor saúde, teria extraído das reformas européias a noção de "competição administrada" proposta para compatibilizar mecanismos de mercado com regulação estatal: "[n]uma ponta o prestador/ financiador de 
serviços e, em outra, o consumidor individual, (...) [com a] (...) inserção no terceiro vértice, do administrador da competição (o sponsor) (...) que pode ser (...) cooperativas (...), etc." (MENDES, 1996, p. 30-31). A estratégia da captação - repasse "definido pelo número de pacientes (...) multiplicado por um valor per capita" - foi especificamente inspirada na experiência holandesa ("na sua forma pura (...), está incorporada, como estratégia microgerencial de contenção de custos, no PAS da Prefeitura Municipal de São Pau10" - MENDES, 1996, p. 208). De outro lado, teria adotado algumas das medidas da reforma canadense, que firmaram-no como projeto popular: a personalização do atendimento, oferta de serviços durante 24 horas, oferta de incentivos aos trabalhadores da saúde com planos de carreira e estímulo à mobilidade profissional. (MENDES, 1996).

Desde a sua implantação, prenunciavam-se, contudo, alguns problemas como: a minimização do atendimento, pois o lucro seria tanto maior quanto menor fosse o custo do atendimento, cabendo à prefeitura - com a participação da comunidade - exercer o controle. Além desta questão, aquela relativa ao controle social nunca foi bem elucidada (COHN et al, 1997), mas o novo modelo de gestão se impôs, "não obstante a intensa polêmica gerada na sociedade (...) [numa tentativa de viabilização de] (...)parceria público/privado na prestação da assistência à saúde, (...)(ELIAS \& COHN, 1998, p.172-3). Sob a fachada da modernização, o PAS caminhou ao lado das exigências do Banco Mundial no que toca à implementação das políticas de saúde pretendidas para os países em desenvolvimento, ou seja, em direção à privatização de parcela das atividades anteriormente de responsabilidade governamental.

Como um "tomado", estas diretrizes caíram sobre as cabeças daqueles que nos NEPIs do DS Tucuruvi/Jaçanã, não tendo "nenhum medo de estar absolutamente contra a corrente política do nosso tempo, (...) resistir[am] ao 'canto da sereia' de que a eficiência e a eficácia só ser[iam]ão alcançadas com a privatização do setor, (...) na ingenuidade de que, sob as rédeas da regulação estatal, dominar[íamos]emos a voracidade do setor privado"' (QUEIROZ \& SALUM, 1997, p. 199).

depoimento 1 - “(..) pode vir quem vier, a minha maneira de trabalhar é aquela, por que a consciência de saúde nossa 'é aquela' e nós vamos indo. (...) pode ser que a gente caia fora para poder sobreviver. Por que eles podem pagar R\$3.500,00 para 0 PAS, mas náo podem pagar para a gente por que nós somos funcionários públicos, por que esses se mantém à margem, por que eles (funcionários públicos) năo valem nada năo é? No dia nós vamos buscando atternativas". 
depoimento 2 - "(...) triplica seu salário para voce se vender e 28000 funcionários năo aderem, alguma coisa aconteceu, foi plantada. Algumas pessoas diziam - Eu năo achei meu CRM no lixo, eu năo achei meu CRP, eu năo achei...! (...) alguma coisa modificou".

depoimento 4 - "(...) um PAS que a gente sabia que era um castelo de areia feito no ar, que era tudo moldado em um sistema de lucro".

depoimento 7 - “(...) tudo o que se avançou voltou para trás com a concepçăo de privatizaçăo mesmo da saúde".

Sujeitando-se às mais indignas formas de pressão institucional, os técnicos do NEPI do DS Tucuruvi/Jaçanã resistiram, não aderiram ao PAS e, não raro, se defrontando com disputas internas, valeram-se de estratégias que articularam, nas suas relações de trabalho e na sobrevivência dos NEPIs, "projetos fundados na solidariedade e na destruição/superação dos mecanismos autoritários e subordinantes" (CAMPOS, 1992, p.93).

depoimento 5 - (...) a gente tamberm tem que entender que, com o govemo Paulo Maluf, muitos enfrentamentos a gente teve com os próprios colegas (...) eu acho que isso melhorou bastante [com o] curso de educaçáo continuada [durante a gestão Maluf] (...) a gente trabalhou as resistencias (...) as nossas dificuldades de relaçăo (...) a gente năo tinha nenhum respaldo (...) [mas] a gente ainda dizia: 'năo entre nessa, vamos mostrar senviço' (...) a gente usava das estratégias todas que nos estavam a mão (...) a gente acertava a mesma linguagem (...) esse trabalho foi feito (...) a gente tem muito orgulho (...)"

depoimento 4- "(...) o fato de ter tido o curso (...) a gente foi vendo o envolvimento cada vez maior das pessoas (...)"

Como veremos a seguir, a resistência, no plano coletivo ou mesmo no plano individual, foi referência fundamental para sustentar a atividade epidemiológica instituída nos primeiros passos da história dos NEPIs. Desafiados a abandonar o que já fora conquistado durante a gestão Maluf, ainda assim, foram capazes de, nos estreitos limites da opressão, ordenar suas açōes em direção a política pública de saúde. 


\section{A HISTÓRIA DOS NEPIS E A DIMENSÃO TECNOLÓGICA: A DIVERSIDADE EM PRÁ- TICA}

A atividade epidemiológica e a constituição de sistemas de informação, peças centrais do trabalho dos NEPIs, vêm sofrendo modificações, conformando-se "diferentes caminhos de compreensão em relação ao planejamento [e ação] em saúde. (...) No Brasil, entre essas grandes tendências, consolidam-se quatro caminhos básicos" (MEHRY, 1995, p. 139), entre eles a proposta da Vigilância à Saúde, "prática ou campo de práticas que conforma ou conformaria um novo modo de pensar e agir em saúde" (TEIXEIRA \& RISI, 1993, p.9), reconhecendo a necessidade de ampliação/redefinição do objeto de trabalho e de efetivamente modificar o sujeito das ações de vigilância, de modo a desenvolver novas formas de lidar com os saberes, métodos e técnicas existentes.

Esta foi a estratégia que a Cooperação Italiana desenvolveu no Município de São Paulo, "para o enfrentamento dos problemas reconhecidos como prioritários (...) [no entendimento de que seria] possivel identificar e detalhar ações que tinham por objetivo modificar o perfil epidemiológico da população do distrito (...) (DIMEANA et al, 1995, p. 29). Era uma prática a ser ainda construída, "informada pelo modelo epidemiológico, que articula, (...) um conjunto de processos de trabalho (...) normalmente disperso[a]s em atividades setorizadas em programas de saúde pública, na vigilância sanitária, na vigilância nutricional e alimentar, no controle de vetores, na educação para a saúde, nas ações sobre o meio ambiente, com ações extra-setoriais, para enfrentar problemas contínuos num território determinado, especialmente ao nível de microárea" (MENDES et al, 1994, p.179).

Mais do que aceitar o desafio de trazer para o Município um novo modo de pensar e agir em saúde, a geståo Erundina se defrontou com a difícil tarefa de integrar ações de vigilância que até então não eram executadas neste nivel e inscritas numa nova concepção. Ainda que de inicio centrado nas atividades de vigilância epidemiológica voltada para o controle de surtos e epidemias, o sistema de informação encaminhou, no processo de municipalização, à ampliação do escopo de ação da epidemiologia. Exigiase dos NEPIs o que PENNA (1993) recomenda: o reconhecimento da necessidade de diálogo para encaminhar a reformulação e a superação das atividades tradicionalmente executadas na saúde pública. Em outras palavras, os NEPIs do DS Tucuruvi/Jaçanã experimentaram no seu desenvolvimento a "passagem que cria a Vigilância Epidemiológica [que] pode ser a chave para nova mudança de rumo na intervenção 
sobre o coletivo: na emergência da Vigilância Epidemiológica está o nascimento possivel de outras vigilâncias, em busca da saúde" (KALICHMAN \& SOUZA, 1994, p. 472).

depoimento 1- "(...) veio de uma proposta (...) contando [com a expectativa de] que a prefeitura assumisse a vigilancia (...), tinha um carater de Vigilancia à Saúde, (...) dizia-se que (...) englobava a Vigilancia epidemiologica, a Vigilancia Zoosanitária, a Vigilância de Alimentos, a questáo de saúde do trabalho, além das quest6es da propria promoçăo em saúde, dos atendimentos nos postos de saúde”.

depoimento 2- "(...) as unidades náo tinham nenhum controle sobre as ocorrencias, ou melhor sobre as intercorrencias com os pacientes de nenhum tipo (...). [Com o decorrer do desenvolvimento do trabalho] (...) a gente começou a descobrir que o NEPI podia fazer uma vigilancia que extrapolava a questăo das doenças e isso (...) aconteceu em um periodo em decorrencia dos mapeamentos da área de risco, aquele processo que nós fizemos de diagnóstico de saúde".

depoimento 4 - "A minha experiencia do NEPI vem de quando eu entrei na Unidade (...) A primeira coisa que eu tentei fazer (...) foi organizar um arquivo completo de Vigilancia Epidemiologica (...) quando a Secretaria tentou ampliar (...) implantar a Vigilancia a Saúde (...) envolvendo (...) outros setores (...) houve uma tentativa de ampliaçåo."

depoimento 5 - "(...) entre setembro e outubro de 1991 (...) a gente procurou trazer o pessoal do COAS, o pessoal do CEPI, que veio fazer esse seminário junto com a gente, na idéia de se trabalhar os profissionais que chegaram pelo concurso com essa nova colocaçăo que a gente trazia frente a constituiçăo de Vigilância em Saúde".

depoimento 7 - “(...) unir aquele trabalho de estar vendo năo a Vigilancia epidemiologica isolada mas estar tentando ver uma outra concepçăo que é a Vigilancia em Saúde. Houve um entrave no ambito politico e também no ambito dos técnicos".

De fato, para PAIM \& TEIXEIRA (1992), a definiçăo inscrita na Lei n 8080/90, na qual a gestão Erundina se baseou, tem caráter bastante abrangente, "(...) no sentido de não se restringir às doenças transmissiveis, muito menos às de notificação compulsória e de envolverem a adoção de medida de controle, o que pode ser entendido como execução no nivel local e considerar uma concepção ampliada de vigilância em saúde (...)" na medida em que integra outras práticas de saúde (PAIM \& TEIXEIRA, 1992, p. 29). A 
reconceituação implícita nessa definição, demanda mudança na ótica restrita da vigilância epidemiológica para a questão mais ampla dos problemas e condições de saúde e por isso é preciso rediscutir as açőes de vigilância epidemiológica no nivel municipal e não simplesmente delegar aos municípios a execução de atividades em sua forma atual (TEIXEIRA \& RISI, 1994). No Municipio de São Paulo, as atividades dos NEPIs, inicialmente centradas na vigilância epidemiológica, eram uma novidade e a base a partir da qual seria dado o salto em direção a vigilância à saúde. Por isso é que na construção do trabalho epidemiológico no DS Tucuruvi/ Jaçanã, acumulam-se, na história dos NEPIs, sobretudo ações de vigilância epidemiológica.

depoimento 3 - "(...) a gente fez um levantamento dos profissionais que foram para lá, eram pessoas envolvidas com vigilancia [epidemiológica] mesmo. Conseguimos] fazer uma estruturaçăo boa, (...) colocar os sanitaristas um em cada unidade do Distrito. (...) [na prefeitura] năo tinham noçăo da dimensăo do que era a vigilancia epidemiológica, (...) nosso principal objetivo foi mostrar para esse pessoal que vigilancia năo era simplesmente s6 o papel, que inclusive o papel era secundário".

depoimento 4 - "(...) a finalidade a gente sabe que era tentar melhorar a conscientizaçăo do que é vigilancia epidemiológica, tanto a nível dos profissionais menos qualificados, como em relaçăo aos profissionais de saúde".

Se de um lado, a vigilância à saúde pode estar preservando as tradicionais características dos sistemas de vigilância epidemiológica, de outro, "busca sinalizar a ampliaçăo das responsabilidades dos serviços de saúde, incluindo al nâo apenas o atendimento aos danos e ao controle de certos riscos, mas tambem o controle das condiçóes de vida e de determinantes ambientais do processo saúde-doença" (BARATA, 1992, p.65). Na história dos NEPIs, se evidencia também esta transição de fronteiras entre a vigilância epidemiológica e vigilância à saúde no encaminhamento inicial do trabalho epidemiológico.

depoimento 6- "(...) desde controlar a morbidade, passando por um diagnóstico local, onde a gente pudesse identificar riscos de adoecer e de morrer da populaçáo da regiăo, isso seria o que eu via como ponto ideal (...) lá nós tínhamos uma área de risco muito grande de transmissáo hidrica, era [muita] favela, (...) problema de criminalidade e violencia, entáo eu via um horizonte que a gente podia traçar, fazer um diagnóstico de maneira muito clara e a partir dal viabilizar as propostas para intervir na realidade, mas 
só como eu já disse a prática era outra, a gente se via amarrado pelas rotinas administrativas e do dia-a-dia das coisas mais emergenciais".

O II Plano Diretor para o Desenvolvimento da Epidemiologia no Brasil, 19951999, observa que há a possibilidade de "concomitância de concepções não equivalentes, que incluem desde 0 aprimoramento do sistema de vigilância epidemiológica - passando pela aglutinação das atividades de vigilância epidemiológica e sanitária, com a inclusão de outras doenças e agravos - até a concepção mais global da vigilância de problemas definidos no nível local, incluindo fatores de risco presentes no ambiente, nas condições de trabalho, nos estilos de vida, etc" (ASSOCIAÇÃO BRASILEIRA DE PÓSGRADUAÇÃO EM SAÚDE COLETIVA, 1995, p. 39). A diversidade de implicações desencadeadas com a mudança substancial do referencial teórico e prático explicam, se não justificam, esta falta de clareza. (FLEURY, 1997).

De outro lado, seria ingenuidade imaginar que mudanças de tal porte conseguissem ser operadas na sua totalidade durante o período de uma gestão de governo, particularmente porque um projeto de mudança se defronta com o "caráter hegemônico (...) da prática médica; das escolas de medicina, enfermagem, odontologia; (...) com aspectos da regulamentação corporativa [e] com a lógica do mercado tão presente no exercício profissional" (CAMPOS, 1997, p.116). Nesse sentido, ao lado dos avanços da prática e das indefinições que preencheram as atividades dos NEPIs durante a gestão Erundina, dificuldades, como as enunciadas a seguir não foram incomuns:

depoimento 7 - "depois do seminário nós demos algumas diretrizes (...), a gente queria avançar na vigiláncia à saúde, do que se partiu em montar uma equipe multiprofissional [para o NEPI] (...), foi um racha - quem é o coordenador, o responsável pelo NEPI? - algumas pessoas achavam que era o médico sanitarista, a gente achava que nåo, tinha que ampliar (...)".

depoimento 3 - "(...) e os distritos nåo tinham um número de profissionais muito grande. (...) a gente nåo tinha espaço físico para trabalhar (...); as viaturas para NEPI nåo existiam".

Todo o processo estratégico que envolveu a distritalização, a territorialização e a criação do sistema de informação só foi de fato legitimado em 15 de junho de 1992 , portanto quase ao final da gestão Erundina, com a promulgação do Decreto $n^{\circ} 31.723 /$ 92 (SÃO PAULO, 1992a) que instituiu "na Secretaria Municipal de Saúde - SMS o Siste- 
ma Municipal de Vigilância à Saúde - SMVS" , estabelecendo as normas para sua implantação e outras providências. Na verdade, entre as disposiçöes do Decreto $n^{\circ} 31.723 /$ 92 está prescrito um conjunto de atividades que só vieram a confirmar o elenco de práticas e saberes que foram gradualmente ordenados no interior dos NEPIs desde a Reforma Administrativa. "Abandonado" na gestão seguinte, o SMVS, sobre o qual dispõe, só foi retomado, enquanto "princípios básicos da organizaçăo e das atividades das áreas de Vigilancia epidemiologica" na Instrução Normativa (IN) 003/96-ASPLAN/PLAN (SÃO PAULO, 1996, p. 29). Porém, o conteúdo das práticas instauradas nos NEPIs do DS Tucuruvi/ Jaçanã durante a gestão Erundina foi tão significativo que, mesmo com o abalo ocasionado durante a gestão Maluf, a atividade epidemiológica não se interrompeu; limitados na busca de expandir o trabalho de vigilância, no seu movimento de constituição, os NEPIs do DS Tucuruvi/Jaçanã sobreviveram, aperfeiçoando a informação interna nas unidades, principalmente no que se referia às informaçōes acerca da vigilância epidemiológica. Isso se revela no conteúdo da IN 003/96 que, estruturando as atribuições dos três niveis, elenca as funçōes dos NEPIs prevendo atividades epidemiológicas e de vigilância em saúde, normatizando atividades diferenciadas para as unidades de Módulos - esfera privada - e de Distritos - esfera pública: às primeiras, a vigilância epidemiológica e às segundas a vigilância à saúde, aquela que seria a novidade gestada no período 1991-1992.

\section{A MUDANÇA, A RESISTÊNCIA E A PERSISTÊNCIA DE TODOS E DE CADA UM}

Ao reconstituir a trajetória dos NEPIs do DS Tucuruvi/Jaçanã, no periodo de 1991-1996, se evidenciaram as marcas de dois projetos políticos e tecnológicos distintos. Os NEPIs nasceram sob a experiência da distritalização em saúde mediada pelo apoio da experiência da Cooperação Italiana no Município de São Paulo. Cresceram até 1993, em torno de um acúmulo de experiências fundadas, de um lado, nas tradicionais atividades de vigilância epidemiológica mas aproximando-se de novos métodos e técnicas em direção à vigilância à saúde. A interrupção formal da municipalização, base para estruturar o setor público municipal sob a lógica do mercado, não se constituiu em obstáculo suficiente para desviá-los da rota. Sobreviveram até 1996, resguardados pelos conteúdos e práticas de que os sujeitos sociais haviam se apropriado ao longo de seu desenvolvimento, aperfeiçoando-se como núcleos de informação. Assim é que, preenchido por um movimento significativo de mudança construido a partir das relaçōes que 
os sujeitos sociais estabeleceram com diferentes projetos de gestão pública municipal, o processo de criação e de desenvolvimento dos NEPIs do DS Tucuruvi/Jaçanã esteve inevitavelmente ligado à experiência de transformação dos sujeitos. Integrados na construção do SUS no Município de São Paulo: articularam-se "ao mesmo tempo, tanto a mudança das pessoas, dos seus valores, da sua cultura ou ideologia, quanto (...) [do] funcionamento das instituições sociais" (CAMPOS, 1994, p.30).

depoimento 1 - "(...) plantamos, construímos"

depoimento 3 - “(..) a gente (...) sentia o envolvimento".

depoimento 4 - "(...) eu senti que a nossa bandeira era a única".

depoimento 5 - "(...) passou a ser um amor (...) um modelo de vida.".

depoimento 6 - "[lutamos] por uma determinada proposta. (...) isso foi modificando alguma coisa nas pessoas".

depoimento 7 - "(...) a gente abraçou (...) eu me modifiquei (...) quem participou realmente colheu frutos e bons frutos”.

A ameaça de desconstrução do SUS, forjou uma prática de resistência concretizada no aperfeiçoamento das atividades de vigilância epidemiológica e das atividades internas nas Unidades, processo em que a degradação e o sentimento de destruição interna eram realidades sempre iminentes, "conforme seus coeficientes de resistência, conforme sua capacidade de engajar-se em projetos que os [distinguiam] da degradação dominante (...).(CAMPOS, 1994, p. 31).

depoimento 1 - "(...) dentro dessa estrutura só cabia a gente recuar".

depoimento 2 - "...) com tudo absolutamente desmontado pelo PAS, como que implodido, a gente resgatou [o trabalho que havíamos iniciado e o levamos para] 0 Centro de Referencia."

depoimento 3 - "(..) por questoes de terrorismo (...) as pessoas foram se desmotivando (...)".

depoimento 4 - “(...) eu tentava agredir".

depoimento 5 - "(...) era o combustível que voce pos no seu carro para poder enfrentar aquela realidade como a gente enfrentou nesses anos de Paulo Maluf". 
No processo de mudança foram "(...) buscar a liberdade até quando[,] internados num campo de concentração[,] é condição indispensável para salvar a humanidade de cada um. Quem desiste, degrada-se, quem persiste, quem insiste, salva-se da ignomínia ainda que nem sempre do sofrimento, capacitando-se, contudo, para sobreviver, depois com um mínimo de saúde mental e auto-estima" (CAMPOS, 1994, p. 31)

depoimento 3 - "(...) o que a gente via era a persistencia de cada um".

depoimento 4 - “(...) eu utilizava meus próprios recursos, (...) mas nunca tentando desanimar".

depoimento 7 - "(...) a gente tem esperança de poder falar, a propria pratica mostrar".

depoimento 5 - "(...) a gente tinha toda [a] informaçăo no dedo, era ainda no tempo do 'ronca', (...) querendo mesmo que a coisa acontecesse".

Maltratados no percurso que abrigou o nascimento do PAS até sua efetiva implantação, "viram seu projeto de vida ser desmontado, sua proposta de trabalho aniquilada.(...) impedidos de administrar suas vidas" (MOTTA, 1997, p.44).

depoimento 2 - "(...) as pessoas estăo [agora] na sua grande parte muito destruídas, muito magoadas, muito inutilizadas (...), as pessoas treinadas, muitas delas, estáo encostadas em escolas, em regionais, parque aquático e sei lá mais o que, é um desperdício de conhecimento que eu diria que é criminoso".

A trajetória dos NEPIs foi enfim estruturada na força de reação coletiva ao projeto de sociedade "onde se debilitou até limites extremos a integração social e se dissolveram os laços sociais e a trama de solidariedade pré-existente" (BORON, 1995, p. 1078).

depoimento 1 - "(...) eu me lembro do último dia quando nós fomos embora, a reaçâo. Foi interessante por que tinham aquelas pessoas já antigas, consideradas muito velhas, muita gente já achava que esse pessoal tinha que se aposentar mesmo, mas todos de máos dadas, mesmo que exorcizando o PAS. E as pessoas deram as máos, alguns falaram, outros rezaram. (...) espero que nesse país possa existir alguma justiça. (...) justiça com o nosso dinheiro, com o nosso trabalho, com o nosso respeito. Por que nos fomos desrespeitados". 
depoimento 2 - "(...) nós năo tínhamos mais voz, năo tinha mais escuta. Acho que a gente participou do que pode, a gente resistiu ao que pode".

depoimento 4 - "(...) a gente sabia de todas as dificuldades que tinham, (...) sabia para onde estava indo as idéias sobre saúde, mas a gente tinha que cumprir o nosso papel até o fim, que era estar sempre envolvido e fazendo o melhor que a gente pudesse, (...) nunca tentando desanimar".

Ao escrever a história dos NEPIs, as equipes dos NEPIs do DS Tucuruvi/Jaçanã buscaram sobreviver para semear a construção futura de novos caminhos, cantando sem o saber:

"Eu sou a fior que o vento jogou no chão, mas ficou um galho pra outra fior brotar. A minha fior, o vento pode levar, mas o meu perfume fica boiando no ar."

(João do Vale e Luiz Vieira)

\section{AGRADECIMENTO}

Ao Prof.Dr.José Luis Fiorin do Departamento de Letras Clássicas e Vernáculas -FFLCH- USP, pela orientação da análise dos documentos.

\section{REFERÊNCIAS BIBLIOGRÁFICAS}

ASSOCIAÇÃO BRASILEIRA DE PÓS-GRADUAÇÃO EM SAÚDE PÚBLICA. Comissão de Epidemiologia. II Plano Diretor para o Desenvolvimento da Epidemiologia no Brasil, 1995-1999. Rio de Janeiro, 1995.

BARATA, R. B. Reorientação das práticas de vigilância epidemiológica. In: SEMINÁRIO NACIONAL DE VIGILÁNCIA EPIDEMIOLÓGICA, 1, Brasília, 1992. Anais. Brasília, 1993, p.63-68.

BARDIN, L. Análise de conteúdo. Lisboa, Edições 70, 1977. 
BARROS, E. Política de saúde no Brasil: a universalização tardia como possibilidade de construção do novo. Ciênc Saúde Coletiva. 1(1):5-17, 1996.

BITTAR, J. O modo petista de govemar. São Paulo, Editora Teoria \& Debate, 1992.

BORÓN, A. A sociedade civil depois do dilúvio neoliberal. In: SADER, E.; GENTILI, P., orgs. Pós-neoliberalismo: as políticas sociais e o estado democrático. São Paulo, Paz e Terra, 1995. p. 24-8.

CAMPOS, G. W. de S. Reforma da reforma: repensando a saúde. São Paulo, HUCITEC, 1992.

CAMPOS, G. W. de S. Considerações sobre a arte e a ciência da mudança: revolução das coisas e reforma das pessoas: o caso da saúde. In: CECÍLIO, L. C. de O., org. Inventando a mudança na saúde. São Paulo, HUCITEC, 1994. (Série Didática, 3) p. 29-87.

CAMPOS, G.W. de S. Análise crítica das contribuições da saúde coletiva e organização das práticas de saúde no SUS. In: FLEURY, S., org. Saúde e democracia: a luta do CEBES. São Paulo, Lemos, 1997. p.113-24.

COHN, A.; ELIAS, P. E. \& JACOBI, P. Participação popular e gestão de serviços de saúde: um olhar sobre a experiência do Município de São Paulo. Saúde em Debate, (38):90-3, 1993.

COHN, A. Mudanças econômicas e políticas de saúde no Brasil. In: LAURELL, A. C., org. Estado e políticas sociais no neoliberalismo. São Paulo, CORTEZ, 1995. p. 225-44.

COHN, A. \& ELIAS, P. E., coord. O processo de implantaçăo do PAS: universalidade ou seletividade no acesso à saúde? Relatório da primeira, Segunda e terceira etapas. São Paulo, Centro de Estudos de Cultura Contemporânea, 1997. [mimeografado]

COSTA, N. do R. O Banco Mundial e a política social nos anos 90. In: COSTA, N. do R.; RIBEIRO, J. M., org. Política de saúde e inovaçåo institucional: uma agenda para os anos 90. Rio de Janeiro. ENSP, 1996. p. 13-29.

COUTO, C. G. O desafio de ser governo: o PT na prefeitura de Sáo Paulo (1989-1992). Rio de Janeiro, Paz e Terra, 1995.

DIMEANA, F. R.; GUIMARÃES, M. do C. L.\& FOCCOLI, E. O desenvolvimento gerencial dos Sistemas Locais de Saúde: a experiência da Cooperação Italiana em Saúde no Brasil. In: TEIXEIRA, C. F.; MELO, C., orgs. Construindo distritos sanitários: a experiência da Cooperação Italiana no Municipio de Săo Paulo. São Paulo, HUCITEC, 1995.

ELIAS, P. E. \& COHN, A. O PAS no Município de Săo Paulo: novos desafios para velhas questōes. RAP, 32(2): 167-84, 1998 
FLEURY, S. A questão democrática na saúde. In: FLEURY, S., org. Saúde e democracia: a luta do CEBES. São Paulo, Lemos, 1997. p.25-44.

GENOINO, J. Petismo versus malufismo. Jomal da Tarde, Såo Paulo, 28 set 1996. [online]. Disponivel na Internet: < http:wnw.genoino.org/pub1/artigos/petismo.htm.

GERSCHMAN, S. A democracia inconclusa: um estudo da reforma sanitéria brasileira. Rio de Janeiro, FIOCRUZ, 1995.

KALICHMAN, A. O.; SOUZA, M. de F. M. de Vigilância à saúde: epidemiologia, serviços e qualidade de vida. In: ROUQUAYROL, M. Z., org. Epidemiologia \& saúro. $4^{2}$ ed. Rio de Janeiro. MEDSI, 1994. p. 467-76.

KOWARICK, L. \& SINGER, A. A experiência do Partido dos Trabalhadores na Prefeitura de São Paulo. Novos Estudos CEBRAP, (35):195-216, 1993.

LAURELL, A. C. Avançando em direção ao passado: a política social do neoliberalismo. In: LAURELL, A. C., org. Estado e polfiticas sociais do neoliberalismo. São Paulo, Cortez, 1995. p.151-224.

MACHADO, H. M. \& BELISÁRIO, S. A. O político e o técnico: as encruzilhadas do planejamento. In: GIOVANELLA, L., org. Planejamento estratégico, programaçáo e orçamentaçáo em saúde: textos de apoio ao ensino da saúde coletiva. Rio de Janeiro, Fundação Oswaldo Cruz, 1992. cap.1, p. 7-13.

MAINGUENEAU, D. Novas tendencias em análise do discurso. $2^{2} \mathrm{ed}$. Campinas, Pontes, 1993.

MENDES, E. V.; TEIXEIRA, C. F.; ARAÚJO, E. C. \& CARDOSO, M. R. L. Distritos sanitários: conceitos-chave. In: MENDES, E. V., org Distrito sanitário: o processo social de mudança das praticas sanitarias do Sistema Único de Saúde. $2^{2}$ ed., São Paulo, Hucitec, 1994.

MENDES, E. V. Uma agenda para a saúde. São Paulo, Hucitec, 1996.

MERHY, E. E. A saúde pública como polftica: Såo Paulo, 1920-1948 os movimentos sanitarios, os modelos tecnoassistenciais e a formaçáo das polfticas governamentais. São Paulo, Hucitec, 1992.

MERHY, E. E. Planejamento como tecnologia de gestão: tendências e debates do planejamento em saúde no Brasil. In: GALLO, E., org. Razáo e planejamento: refiexöes sobre politica, estratłgia e liberdade. São Paulo, Hucitec, 1995. p. 117-149. (Saúde em Debate - Série Didática).

MINAYO, M. C. de S. O desafio do conhecimento: pesquisa qualitativa em saúde. $3^{a}$ ed., São Paulo, Hucitec, $1994 a$. 
MINAYO, M. C. de S. Pesquisa social: teoria, método e criatividade. $3^{\text {a }}$ ed., Petrópolis, Vozes, 1994b.

MOTTA, C., org. PAS: o avesso da saúde - de como o sUS foi negado aos paulistanos. São Paulo, SIMESP, 1997. p.3-58.

OLIVEIRA, J. E. G. de OPAS e o neoliberalismo. In: MOTTA, C., org. PAS: o avesso da saúde - de como o SUS foi negado aos paulistanos. São Paulo, SIMESP, 1997. p.95-109.

PAIM, J. S. P. \& TEIXEIRA, M. G. L. Reorganização do sistema de vigilância epidemiológica na perpectiva do Sistema Único de Saúde (SUS). Inf Epidemiol. SUS, 1, (5):27-57, 1992.

PENNA, M. L. F. Epidemiologia e serviços de saúde: momento atual. In: SEMINÁRIO NACIONAL DE VIGILÂNCIA EPIDEMIOLÓGICA, $1^{\circ}$, Brasília, 1992. Anais. Brasília, 1993, p. 53-62.

POSSAS, C. de A. A articulação público-privado e os cuidados com a saúde dos pobres: implicações das políticas de ajuste estrutural na América Latina. In: EIBENSCHUTZ, C., org. Polltica de saúde: o público e o privado. Rio de Janeiro. FIOCRUZ, 1996. p. 49-65.

QUEIROZ, V. M. de \& SALUM, M. J. L. Globalização econômica e a apartação na saúde: reflexão crítica para o pensar/fazer na enfermagem. In: CONGRESSO BRASILEIRO DE ENFERMAGEM, 48. Anais. São Paulo, 1997. p. 190-207.

SADER, E. A hegemonia neoliberal na América Latina. In: SADER, E.; GENTILI, P., orgs. Pós-neoliberalismo: as políticas sociais e o estado democrático. São Paulo, Paz e Terra, 1995a. p.35-7.

SADER, E. O anjo torto: esquerda (e direita) no Brasil. São Paulo, Brasiliense, 1995b.

SÃO PAULO (Cidade). Leis etc. Portaria n 1109 de 5 de julho de 1990. Considerando o processo de descentralização de Secretaria Municipal de Saúde, a necessidade de implantação do Sistema Único de Saúde e da participação da comunidade, resolve delegar à Virgínia Junqueira as competências de coordenação, planejamento e controle das ações dos serviços de saúde, além de auxiliar o Secretário Municipal de Saúde. Diário Oficial do Municipio. São Paulo, 5 julh 1990, p.19.

SÃO PAULO (Cidade) Secretaria Municipal da Saúde. Centro de Epidemiologia, Pesquisa e Informação. Proposta de atribuiç̧es de vigilancia à saúde nos diferentes niveis administrativos da Secretaria Municipal de Saúde. São Paulo, 1991. [mimeografado] 
SÃO PAULO (Cidade). Leis etc. Decreto n 31723 de 15 de junho de 1992. Institui na Secretaria Municipal de Saúde - SMS o Sistema Municipal de Vigilância à Saúde SMVS, estabelece normas para sua implantação, e dá outras providências. Legislaçăo do Estado de Săo Paulo e do Município de Săo Paulo. São Paulo, 1992a. p. 587-89.

SÃO PAULO (Cidade). Leis etc. Decreto $n 32773$ de 10 de dezembro de 1992. Consolida as disposições relativas à organização da Secretaria Municipal da Saúde - SMS, e dá outras providências. Legislaçăo do Estado de Săo Paulo e do Município de Săo Paulo. São Paulo, 1992b. p.1178-1208.

SÃO PAULO (Cidade). Leis etc. Instrução Normativa n 003/96 - ASPLAN/PLAN de 31 de maio de 1996. Divulga as funções e atribuiçōes dos níveis: central, regional, distrital, local e Módulos do PAS quanto à Informação, Vigilância em Saúde, Faturamento e Planejamento. Diário Oficial do Municipio. São Paulo, 31 maio 1996. p.23-4.

SEGATTO, N. \& ROVAI, R. Por trás da máscara. São Paulo, Editora Brasil, 1996.

TEIXEIRA, C. F. \& PINTO, L. L. A formação de pessoal em vigilância à saúde. Inf. Epidemiol. SUS, 2(6):5-21, 1993.

TEIXEIRA, M. da G. \& RISI, J. B. Vigilância epidemiológica. In: BRASIL. MINISTÉRIO DA SAÚDE. Divisão Nacional de Epidemiologia. Guia de vigilancia epidemiológica. Brasília, Centro de Documentação do Ministério da Saúde, 1994. p. 11-24.

UNGLERT, C. V. de S. Territorialização em sistemas de saúde. In: MENDES, E. V., org. Distrito sanitário: o processo social de mudança das práticas sanitárias do Sistema Único de Saúde. $2^{2}$ ed. São Paulo, Hucitec, 1994. p. 221-36. 
CHANGE, RESISTENCE AND PERSEVERANCE OF NEPI'S TECHNICALS IN A HEALTH DISTRICT OF SÃO PAULO CITY

SUMMARY: The object of this work is the trajectory of the Research and Information Centers (NEPI) of the extinct Health Districts Tucuruvi/Jaçana of the Municipal Office of Health of São Paulo City, between 1991 and 1996. The theoretical reference is the techno-assistencial model. The analysis concerned: the relationship between social actors and public administration; the consequences of this relationship to the health domain (political dimension) and finally the relationship between these social actors and the health nuclear knowledge and practices (technological domain). This process allowed the search for the "constitutive heterogeneity" between empirical and theoretical data. The analysis shows that two distinct projects have nurtured the NEPIs trajectories. They were originated under the influence of an Italian cooperation and the Sanitary Reform principles; the political project of the new Brazilian Unified Health System (SUS); and the health "territorialization" information system. The NEPIs grew until 1993 developing epidemiological traditional surveillance trying to broaden their activities. After 1993, under another municipal administration, the "territorialization" process was interrupted and the public health sector was conducted by the mercantilist logics of the World Bank . This was not sufficient to deviate the original route. The NEPIs survived until 1996 inspired by the contents and practices built in the former administration. Although they were limited in their intent to amplify health surveillance, the information system was improved and all the efforts were made to maintain the surveillance activities. The relationship between social actors and the distinct public administration projects has organized the NEPIs trajectory at the cost of collective and individual changes. To the limits of their resistance, these social actors have faced political adversities reacting collectively to the point of developing a "new way of thinking and acting in health".

KEY WORDS: health services; epidemiological action; public policies; Unified Health System; health social practices. 